\title{
Efectividad de la vacuna antigripal en la prevención de gripe grave (hospitalización) en un área sanitaria. Temporada 2015-2016
}

\author{
Effectiveness of the influenza vaccine in the prevention of severe influenza \\ (hospitalization) in a health area. Season 2015-2016
}

\author{
Pena Martínez $\mathrm{M}^{1}$, Felpeto Nodar I, ${ }^{1,2}$, Pérez Castro $\mathrm{S}^{3,4}$, del Campo Pérez VM ${ }^{1,2,4}$ \\ ${ }^{1}$ Escuela Universitaria de Enfermería Meixoeiro - Universidad de Vigo \\ ${ }^{2}$ Servicio de Medicina Preventiva. Complexo Hospitalario Universitario de Vigo. Sergas \\ ${ }^{3}$ Servicio de Microbiología. Complexo Hospitalario Universitario de Vigo. Sergas \\ ${ }^{4}$ Instituto de Investigación Biomédica Galicia Sur. Vigo
}

\section{Resumen}

Objetivos: El objetivo principal de este estudio fue determinar el grado de efectividad de la vacuna antigripal para prevenir el ingreso por gripe en la temporada 2015-2016 en el área de Vigo. Además se analizó la evolución de las hospitalizaciones por gripe de dicha temporada en el área sanitaria.

Métodos: Estudio observacional de casos y controles negativos. Los casos se seleccionaron de los pacientes hospitalizados por gripe con una prueba microbiológica de virus gripal positiva. Se emparejaron según edad y sexo con los controles, pacientes ingresados con cuadro gripal con prueba microbiológica negativa frente al virus de la gripe. Sobre el total de pacientes seleccionables se aplicaron una serie de criterios de inclusión y exclusión y tras ello se determinó la efectividad vacunal. Además se analizaron las principales características de los ingresos hospitalarios con confirmación positiva. Se analizó la evolución clínica, el manejo terapéutico, la duración de la hospitalización y las complicaciones.

Resultados: Durante la temporada estudiada en el área de Vigo circularon los virus $\mathrm{A}(\mathrm{H} 1 \mathrm{~N} 1)$ pdm09 y el virus $\mathrm{B}$, predominando las infecciones por el virus pandémico. Ingresaron 262 pacientes con gripe confirmada, con una distribución similar por género y una media de edad de 53,9 años. Más del $70 \%$ de los pacientes hospitalizados presentaban factores de riesgo. Además cerca de la mitad de los pacientes ingresados sufrieron complicaciones gripales graves y un $8 \%$ falleció durante la evolución de la enfermedad.

La efectividad vacunal obtenida es elevada y significativa para prevenir el ingreso hospitalario, el ingreso grave (con complicaciones), el ingreso en UCl y frente a todos los subtipos virales. No se demostró una efectividad significativa para prevenir el fallecimiento por gripe ni la hospitalización por gripe en mayores de 75 años de edad.

Conclusiones: La vacuna antigripal de la temporada 2015-2016 fue efectiva para prevenir el ingreso hospitalario por gripe en el Área de Vigo. Destaca la efectividad alcanzada para prevenir el ingreso en UCl y frente al tipo viral B. Palabras clave: Gripe estacional. Vacuna antigripal. Efectividad vacunal. Estudio de casos y controles.

\section{Introducción}

La gripe es una enfermedad aguda inducida por un grupo de virus de la familia Orthomyxoviridae ${ }^{1}$ que afecta a las vías respiratorias. Esta enfermedad es un grave problema de salud pública debido a su gran poder de transmisión y, aunque puede cursar de manera leve, en ocasiones deriva en complicaciones graves e incluso puede llevar a la muerte². Tal es la gravedad de esta patología que se estima que entre el 10 y el 20\% de la población se ve afectada cada año en

\begin{abstract}
Objectives: The main objective of this study was to determine the degree of effectiveness of the influenza vaccine to prevent influenza admission in the 2015-2016 season in the Vigo area. In addition, the evolution of hospitalizations due to influenza of said season in the health area was analyzed. Methods: Observational study of negative cases and controls. Cases were selected from patients hospitalized for influenza with a microbiological test of positive influenza virus. They were matched according to age and sex with the controls, patients admitted with influenza-like-illness with negative microbiological test against influenza virus. A series of inclusion and exclusion criteria were applied to the total number of eligible patients and after that the vaccine effectiveness was determined. In addition, the main characteristics of hospital admissions with positive confirmation were analyzed. The clinical evolution, the therapeutic management, the duration of the hospitalization and the complications were analyzed.
\end{abstract}

Results: During the 2015-2016 season in the Vigo area, the $A(\mathrm{H} 1 \mathrm{~N} 1)$ pdm09 virus and the $B$ virus circulated, predominantly pandemic virus infections. There were 262 patients with confirmed influenza, with a similar distribution by gender and an mean of age 53.9 years. More than $70 \%$ of hospitalized patients had risk factors. About half of the patients admitted suffered serious influenza complications and $8 \%$ died during the course of the disease. The vaccination effectiveness obtained is high and significant to prevent hospital admission, severe admission (with complications), admission to ICU and to all viral subtypes. No significant effectiveness was shown to prevent death from influenza or hospitalization for influenza in people over 75 years of age.

Conclusions: The influenza vaccine of the 2015-2016 season was effective in preventing hospital admission due to influenza in the Vigo area. It highlights the effectiveness achieved to prevent admission to the ICU and against type $B$ virus.

Keywords: Seasonal influenza. Flu vaccine. Vaccine effectiveness. Casecontrol study.

España ${ }^{3}$, encontrando las mayores tasas de hospitalización, mortalidad y complicaciones asociadas en los mayores de 65 años de edad 4 .

En España la temporada 2015-2016 ha sido de baja intensidad, con una duración de once semanas y un inicio tardío, alcanzando su mayor pico a finales del mes de febrero y finalizando en la última semana de marzo. Predominó la circulación del virus pandémico, $A(H 1 N 1) p d m 09$, con una pos- 
terior modificación en el patrón, que supuso un predominio del virus B. Además, durante esta temporada las mayores tasas de incidencia acumulada se observaron entre el grupo de edad de 0 a 4 años, aunque la mayor proporción de hospitalizaciones se concentró en los mayores de 64 años 5 . La medida más efectiva para disminuir la morbilidad y mortalidad de la gripe, es la vacunación de las personas de los grupos de riesgo ${ }^{6}$. Debido a los cambios que se producen en los virus influenza, la composición de la vacuna debe ser reformulada cada año, y, por lo tanto, se debe administrar la vacuna de manera anual.

Para la temporada 2015-2016 la recomendación de la OMS 7 para la composición de la vacuna antigripal trivalente, era la siguiente: cepa análoga A/California/7/2009 (H1N1) pdm09, cepa análoga A/Switzerland/9715293/2013 (H3N2) y cepa análoga B/Phuket/3073/2013 (linaje Yamagata).

Siguiendo estas recomendaciones, en la Comunidad Autónoma de Galicia, la Consellería de Sanidade puso en marcha la campaña anual de vacunación antigripal, de dos meses de duración (19 de octubre a 19 de diciembre de 2015), ofreciéndola a todos los grupos de riesgo ${ }^{6}$. Durante dicha campaña se administraron 485.593 dosis de vacuna antigripal, $22.000^{8}$ más que en la temporada anterior, sin embargo, no se alcanzaron los objetivos de cobertura vacunal en ningún grupo de riesgo. Además en el área en el que se llevó a cabo el estudio, el área de Vigo, se obtuvo la tasa de vacunación, en mayores de 65 años, más baja de toda la comunidad, un $49,8 \%$.

Debido a las constantes modificaciones que se suceden en los virus de la gripe la vacuna debe reformularse anualmente. Como consecuencia, la efectividad de la vacuna antigripal estacional varía cada temporada en función del grado de concordancia entre los virus incluidos en la vacuna y los virus que realmente circulan. Por esto, conocer la efectividad de la vacunación es prioritario en muchos países, ya que ayuda a establecer la verdadera capacidad de prevención de la vacuna antigripal y permite el planteamiento de estrategias vacunales dirigidas a los colectivos con mayor efectividad 0 incluso la adopción de otras medidas como la quimioprofilaxis.

Actualmente los estudios más eficientes para determinar la efectividad vacunal son los estudios de casos y controles negativos que nos aportan mucha información pese a estar potencialmente sujetos a un gran número de sesgos como los sesgos de selección, que pueden ocurrir durante la selección de los casos y controles, o los sesgos de información, errores que pueden cometerse durante la recogida de datos.

Dada la necesidad de monitorizar la efectividad de la vacuna surge en Europa un sistema capaz de estimar ésta a tiempo real, denominado I-MOVE (Influenza-Monitoring Vaccine Effectiveness), promovido por el Centro Europeo para la Prevención y Control de Enfermedades (ECDC) ${ }^{9}$. El Sistema de Vigilancia de Gripe en España (SVGE), participa en este proyecto europeo mediante diferentes redes centinelas en- tre las que no se encuentran las Comunidades de Galicia ni Murcia, que utilizan otros sistemas. El sistema utilizado para monitorizar la evolución de la gripe estacional cada temporada en Galicia se basa en: las Ilamadas por gripe e infección respiratoria aguda (IRA) al 061, los registros informatizados de gripe en Atención Primaria del SERGAS, la información microbiológica y la información sobre ingresos hospitalarios con gripe confirmada. Por esto, pese a tener datos sobre la efectividad vacunal a nivel europeo y también a nivel estatal, no existen datos acerca de la efectividad vacunal en Galicia ni sobre la evolución de la gripe y las hospitalizaciones en el Área de Vigo.

El estudio que se plantea pretende estimar la efectividad de la vacuna antigripal en prevención de casos graves confirmados por laboratorio en el Área de Vigo durante la temporada 2015-2016, ya que se hace necesario comprobar, para cada temporada, la efectividad de la vacuna, y los datos disponibles de la temporada anterior (2014-2015) nos mostraban una efectividad muy baja.

\section{Métodos}

Inicialmente se realizó un estudio descriptivo de las hospitalizaciones con confirmación microbiológica para virus gripales para caracterizar los ingresos por gripe en el Área de Vigo durante la temporada 2015-2016. Tras ello se realizó un estudio analítico observacional de casos y controles con el objetivo de determinar la efectividad de la vacuna antigripal para prevenir el ingreso hospitalario por gripe, en el mismo ámbito geográfico y temporal.

Se llevó a cabo un estudio descriptivo observacional utilizando la información de los ingresos con identificación microbiológica de algún virus gripal durante la temporada 2015-2016, disponible en el registro de enfermedades de declaración obligatoria (SXNOE-Vixia) del Complexo Hospitalario Universitario de Vigo (CHUVI). Se incluyeron todos aquellos pacientes que durante la temporada 2015-2016 presentaron una prueba microbiológica positiva para algún virus gripal con ingreso hospitalario en alguno de los hospitales de atención especializada del CHUVI. Para determinar microbiológicamente la presencia del virus se llevaron a cabo dos tipos de pruebas sobre las muestras recogidas: la inmunofluorescencia y, mayoritariamente, la reacción de cadena de la polimerasa con transcripción inversa en tiempo real (RT-PCR).

Posteriormente se realizó un estudio observacional de casos y controles negativos para gripe, con el objetivo de determinar la efectividad de la vacuna antigripal, en la prevención de la hospitalización por gripe.

La población diana fue la formada por los residentes en todos aquellos municipios que componen el Área de Vigo con adscripción al CHUVI durante la temporada de gripe estacional 2015-2016.

Se definió caso como aquel paciente ingresado en el CHUVI durante los meses de temporada de gripe estacional con 
identificación microbiológica de algún virus influenza. Se aplicaron los siguientes criterios de exclusión:

- Pacientes con sospecha de infección de origen nosocomial.

- Pacientes con fecha de nacimiento posterior al 31 de diciembre de 2014 (no indicación de vacunación).

- Pacientes con residencia fuera del Área del Vigo.

Se consideró control a aquellos pacientes ingresados con diagnóstico de sospecha de cuadro gripal y pruebas microbiológicas negativas para virus influenza. Se seleccionaron dos controles por cada caso, del mismo sexo y con una diferencia de edad máxima de cinco años y se aplicaron los mismos criterios de exclusión.

Para los casos y los controles se recogieron las siguientes variables: edad, sexo, fecha de confirmación microbiológica positiva o negativa del virus gripal, vacunación frente a la gripe y fecha de vacunación.

Se utilizó SPSS 15.0 como software. Inicialmente se realizó un análisis descriptivo de los datos, para ello las variables cualitativas se presentaron según la frecuencia y el porcentaje. Para las variables cuantitativas se utilizó la media y desviación estándar, sustituidas por la mediana y los percentiles cuando estas no seguían una distribución normal.

Se realizaron pruebas que permitiesen comparar la relación entre diferentes variables: chi cuadrado de Pearson $\left(x^{2}\right) 0$ el test exacto de Fisher en su defecto, test $t$ de student y el análisis de varianza (ANOVA). De esta forma se compararon los valores entre los grupos para descubrir la existencia de diferencias y si estas eran o no significativas. Para determinar el nivel de significación se utilizó un valor de a de 0,05. Se calculó la efectividad vacunal con Epidat 3.1, un programa elaborado por la Consellería de Sanidade (Xunta de Galicia) que permite realizar análisis estadístico y epidemiológico de datos tabulados. Se utilizó la siguiente fórmula para calcular la efectividad, utilizando la odds ratio y ajustando el valor con intervalos de confianza del 95\% (IC 95\%):

Efectividad vacunal $=(1-0 d d s$ Ratio $) \times 100$

\section{Resultados}

Por los ingresos hospitalarios, la temporada de gripe estacional 2015-2016 en el Complejo Hospitalario Universitario de Vigo (CHUVI) abarcó desde la semana 47 de 2015 hasta la 25 de 2016. La distribución temporal de los casos presenta variaciones destacables en su curva epidémica, con un ascenso más marcado en el número de casos entre las semanas 4 y 6 y un pico en la semana 7 (mes de febrero).

La tasa de hospitalización por gripe, durante el total de la temporada, para el área completa ha sido de 59,1/100.000 habitantes, con variaciones entre 53 y 110 según zonas sanitarias de atención integrada.

En la gráfica 1 podemos observar las diferencias de frecuencia de aparición de los casos entre los diferentes tipos virales presentes a lo largo de la temporada.
El A(H1N1)pdm09 es el subtipo de primera aparición, con una frecuencia mayor en la curva epidémica. De forma más tardía y con una frecuencia menor aparecen el resto de subtipos virales. La aparición del virus B no sucede hasta alcanzar el máximo pico de gripe estacional por el virus pandémico A(H1N1) pdm09 en la semana 6.

La distribución por sexo de los casos es similar, 129 casos en mujeres (49,3\%); de las cuales un 16,3\%, es decir 21 mujeres, estaban embarazadas en el momento del ingreso hospitalario. Por otra parte, la distribución según la edad muestra una media de 53,4 años, con una desviación estándar de 27,3 y un rango de edad entre los 19 días y los 92 años de edad. Hay un mayor número de hospitalizaciones en las edades más extremas de la vida, la infancia y la vejez. Si comparamos la distribución de los casos según la edad y sexo (gráfica 2), se observa una clara diferencia entre los 20 y 39 años de edad, con una frecuencia mayor en mujeres que corresponderían con las mujeres embarazadas.

Analizando los días transcurridos desde el inicio de los síntomas hasta el ingreso obtenemos una demora de ingreso con una mediana de 3 días $(0,36)$. Diferenciando los datos por género observamos un ingreso tras los primeros síntomas más temprano en las mujeres que en los hombres $(3,3$ días vs 4,4 días, $p=0,04$ ).

La mediana de días de ingreso en el hospital es de 7 días con un máximo de 125 y un mínimo de un día de ingreso en el hospital. Si cuantificamos la media de estancia hospitalaria según el sexo, observamos que los varones presentan ingresos con mayor número de días de estancia, con diferencias estadísticamente significativas (13,3 días vs 9,6 días, $p=0,048)$. Comparando los días de estancia con la edad de los pacientes (gráfica 3), se constata que existe una relación clara, mostrando un mayor número de ingresos y de mayor duración en edades más avanzadas de la vida.

En cuanto al tratamiento, de los 262 casos de ingreso con gripe confirmada en el CHUVI, 156 (59,5\%) fueron tratados con un fármaco antiviral, en todos los casos oseltamivir. La pauta de tratamiento fue la estándar (75 mg por vía oral cada 12 horas salvo insuficiencia renal que se administró cada 24 horas). La duración media del tratamiento fue de 6,2 días.

36 pacientes, el $13,7 \%$ de los casos, necesitaron ser ingresados en la Unidad de Cuidados Intensivos (UCI) 0 en la Unidad de Cuidados Intensivos Pediátricos (UCIP) durante la hospitalización. Un 44,4\% de los pacientes ingresados en la UCI precisó ventilación mecánica invasiva (VMI) con un mayor número de días de ingreso hospitalario en aquellos pacientes que precisaron VMI (24,3 días) en comparación con aquellos que utilizaron otras medidas de soporte respiratorio no invasivo (12,8 días) o ninguna medida de soporte ventilatorio utilizada (5 días) $(p=0,04)$.

70 pacientes $(26,7 \%$ del total) de los que ingresaron por gripe habían recibido previamente la vacuna antigripal. Este dato cobra mayor relevancia si observamos dicha frecuencia según los grupos de riesgo (tabla 1). 


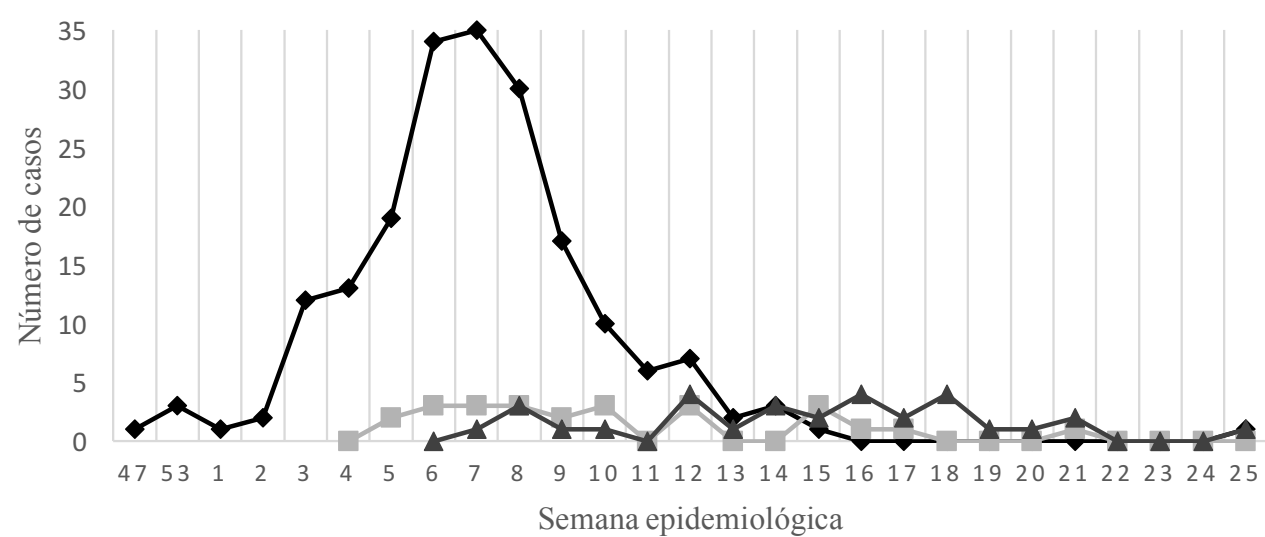

$\multimap$ AH1N1pdm09 $\rightarrow$ AH3 $\longrightarrow$ B

Gráfica 2. Distribución de los casos según sexo y edad.
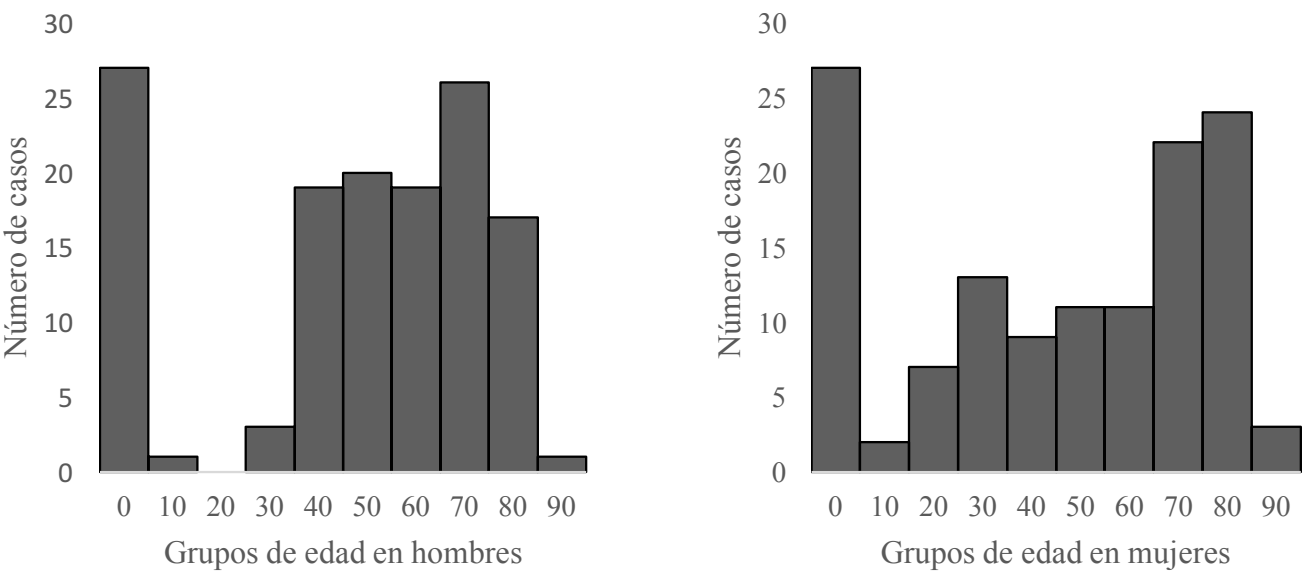

Gráfica 3. Relación entre la edad de los pacientes y los días de estancia hospitalaria.

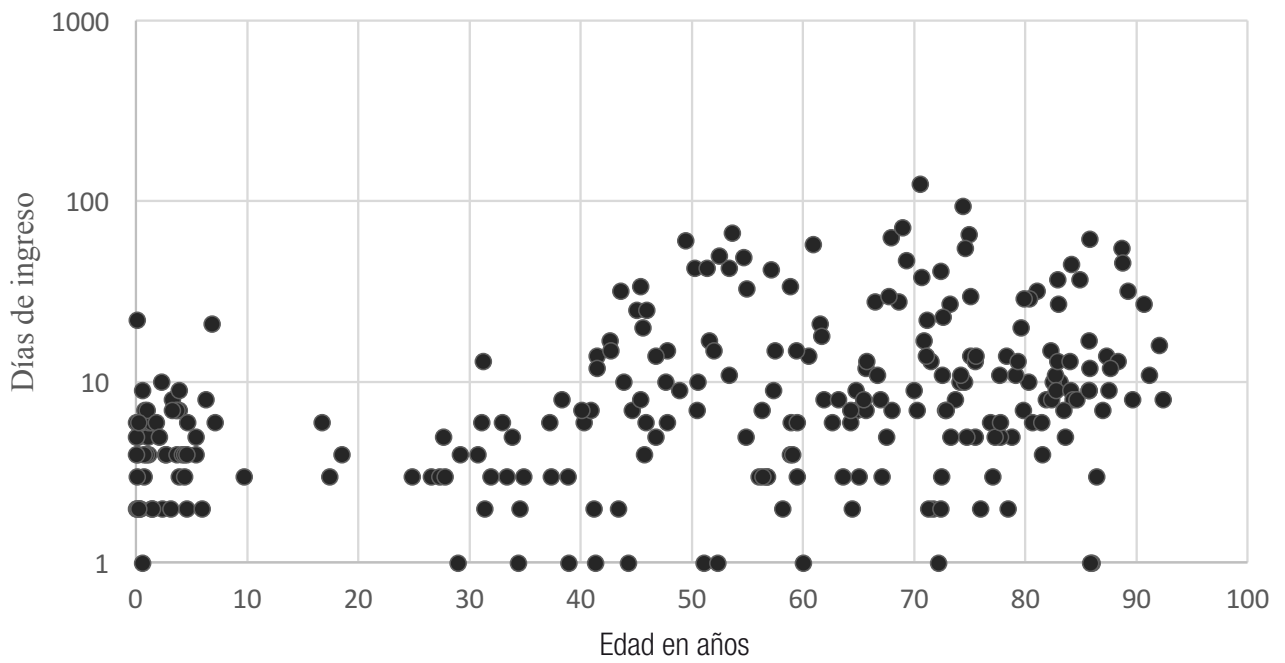


Tabla 1. Tasas de vacunación según grupos de riesgo en el Área de Vigo.

\begin{tabular}{|c|c|}
\hline \multicolumn{2}{|c|}{ Frecuencia de vacunación } \\
\hline Grupo de edad entre los 60 y 65 años & $28,6 \%$ \\
\hline Mayor de 65 años & $50,5 \%$ \\
\hline Gestantes & $14,3 \%$ \\
\hline Factores de riesgo & $36,3 \%$ \\
\hline
\end{tabular}

Tabla 2. Exitus según tipo viral.

\begin{tabular}{|c|c|c|c|c|}
\hline Exitus & Sí & No & Total & p-value \\
\hline Tipo viral & & & & \\
\hline $\begin{array}{c}\text { A (H1N1) } \\
\text { pdm09 }\end{array}$ & $19(9,6 \%)$ & $\begin{array}{c}178 \\
(90,4 \%)\end{array}$ & $197(100 \%)$ & \\
\hline A (H3N2) & $0(0 \%)$ & $25(100 \%)$ & $25(100 \%)$ & \\
\hline ANS & $2(22,2 \%)$ & $7(77,8 \%)$ & $9(100 \%)$ & \\
\hline B & $0(0 \%)$ & $31(100 \%)$ & $31(100 \%)$ & \\
\hline & & & & 0,045 \\
\hline
\end{tabular}

Tabla 3. Análisis descriptivo de los casos y controles.

\begin{tabular}{|c|c|c|}
\hline & $\begin{array}{c}\text { Casos } \\
(\mathrm{n}=209)\end{array}$ & $\begin{array}{c}\text { Controles } \\
(\mathrm{n}=424)\end{array}$ \\
\hline Sexo & & \\
\hline Mujeres & $103(49,3 \%)$ & $234(50,4 \%)$ \\
\hline Hombres & $106(50,7 \%)$ & $230(49,6 \%)$ \\
\hline Grupos de edad & & \\
\hline$\leq 5$ & $24(11,5 \%)$ & $38(8,2 \%)$ \\
\hline $5-59$ años de edad & $79(37,8 \%)$ & $162(34,9 \%)$ \\
\hline$\geq 60$ años & $106(50,7 \%)$ & $264(56,9 \%)$ \\
\hline Municipio de residencia & & \\
\hline Vigo & $107(51,2 \%)$ & $243(52,3 \%)$ \\
\hline Otros & $102(48,8 \%)$ & $230(49,6 \%)$ \\
\hline Tipo viral & & \\
\hline A (H1N1) pdm 09 & $160(76,6 \%)$ & \\
\hline A (H3N2) & $18(8,6 \%)$ & \\
\hline ANS & $8(3,8 \%)$ & \\
\hline B & $23(11,0 \%)$ & \\
\hline
\end{tabular}

En el $43,5 \%$ de los casos de hospitalización por gripe se presentó alguna complicación secundaria derivada siendo la más frecuente la neumonía (29\%) y las de mayor riesgo, por su relación significativa con el riesgo de fallecer: el síndrome de distress respiratorio (8,8\%) 0 el fallo multiorgánico $(3,8 \%)$.

La proporción de fallecimientos durante el ingreso en el CHUVI fue de un 8\% (21 pacientes), pudiendo atribuir en todos los éxitus un papel a la infección por virus influenza, directamente causal o descompensando patologías previas. Al analizar la relación entre la vacunación y el fallecimiento, no se observa una relación significativa entre éstas $(p=0,01)$. A pesar de esto, se destaca que el $66,7 \%$ de los fallecidos no había recibido la vacuna antigripal.

Un $61,9 \%$ de los fallecidos eran mayores de 65 años de edad, observándose diferencias estadísticamente significativas para el riesgo de morir en estos pacientes ( $p=0,59)$. Además, se observaron diferencias significativas en la mortalidad según el tipo de virus (tabla 2), asociándose con el virus pandémico (90,5\% de los fallecidos) y los A no tipados, no registrando fallecimientos en ingresos por virus tipo $B$ o A(H3N2).

Al observar las fechas de vacunación en los sujetos del estudio (casos o controles) se constata una mayor frecuencia de administración durante las primeras semanas de la campaña de vacunación, en las dos primeras semanas se administraron más del $50 \%$ de las registradas y al finalizar el primer mes de campaña, están vacunados el 80\% del total de los vacunados del estudio.

Para la realización del estudio de casos y controles se asignaron dos controles por cada caso, del mismo sexo y con una diferencia de edad que oscilaba en menos cinco años. En la tabla 3 puede verse el análisis descriptivo de ambos grupos.

Al analizar la efectividad vacunal para prevenir el ingreso, se obtuvieron los datos reflejados en la tabla 4, que muestran una efectividad de la vacuna antigripal para la temporada 2015-2016 en el Área de Vigo significativa, de 34,7\%.

Para prevenir complicaciones graves se obtuvo una efectividad significativa de $44,7 \%$ y en cuanto al ingreso en la Unidad de Cuidados intensivos, la efectividad obtenida es muy significativa, 79,8\% (gráfica 4).

La efectividad de la vacuna antigripal para prevenir el ingreso, comparada por sexos, muestra una efectividad significativa y elevada en hombres, 38,7\%, superior a la alcanzada en las mujeres, 30,9\%.

Se comparó la efectividad de la vacuna por subgrupos de edad, obteniéndose una efectividad más alta y significativa en los mayores de 60 con un valor de 37,0\%, no alcanzando significación estadística en los otros grupos.

La efectividad comparada según el subgrupo viral, muestra una efectividad significativa para todos los subtipos analizados. Frente al tipo viral B la vacuna para la temporada 2015-2016 presenta la efectividad más alta. 


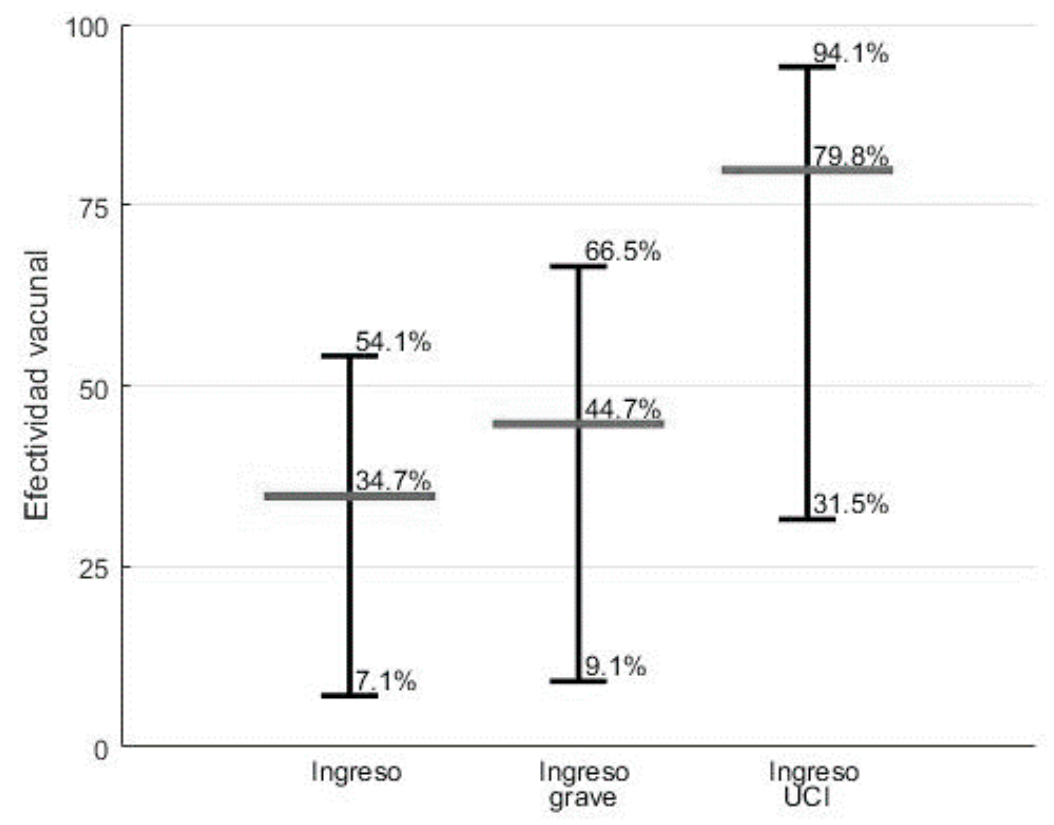

\section{Discusión}

Los resultados obtenidos durante la realización del presente estudio, demuestran que la vacuna antigripal administrada durante la temporada fue efectiva para prevenir la hospitalización con confirmación microbiológica de virus gripal en el Área de Vigo (34,7\%), especialmente para prevenir el ingreso en la Unidad de Cuidados Intensivos y frente al tipo viral B.

Los resultados concuerdan en mayor o menor grado con estudios elaborados siguiendo metodologías similares para la misma temporada. En Europa se llevó a cabo una investigación por el Centro Europeo para la Prevención y Control de Enfermedades (ECDC) con el objetivo de medir la efectividad de la vacuna dentro del programa I-MOVE' ${ }^{9}$, en atención primaria de salud, y el resultado indica una efectividad vacunal similar a nuestro estudio, aunque ligeramente superior, 46,3\% (IC 95\%: 4,9 - 69,7). Sin embargo, un estudio elaborado por Zhang Y. et al. en Pekín ${ }^{10}$ siguiendo la misma metodología que el presente, determinó una efectividad vacunal no significativa -37,9\% (IC 95\%: -103,3 - 6,5) que atribuye la baja efectividad de la vacuna a la falta de correspondencia de la composición de ésta con las cepas circulantes en Pekín.

La temporada de gripe estacional en Vigo comenzó en la semana 47 de 2015 y se prolongó hasta la semana 25 de 2016, produciéndose un mayor número de ingresos hospitalarios durante las semanas seis y once. Ha estado caracterizada por la circulación del virus pandémico $A(\mathrm{H} 1 \mathrm{~N} 1)$ pdm09 con la posterior aparición y aumento de las infecciones causadas por el subtipo B, como en el resto de España y Europa ${ }^{5}$. Esto contrasta con los resultados obtenidos en el estudio realizado sobre la temporada de gripe estacional 2014-2015 en el Área de Vigo por Canoa I'1; aquella tem- porada fue atípica, ya que se caracterizó por una circulación de virus gripales con ausencia de circulación del virus pandémico $A(H 1 N 1) p d m 09$, y dos ondas gripales sucesivas, con distintos virus circulantes: A(H3N2) y B. Los resultados de efectividad obtenidos fueron muy bajos con un $2 \%$ de efectividad global, no significativa.

Las cepas incluidas en la vacuna correspondieron con las cepas que circularon durante la temporada, lo que justifica la efectividad alcanzada por la vacuna en el Área de Vigo. El subtipo viral para el que la vacuna de la temporada 20152016 en nuestra Área alcanzó la mayor efectividad $(67,1 \%)$ es el subtipo $B$, pese a la utilización de vacuna trivalente, con sólo un linaje del virus $B$.

La efectividad de la vacuna para el virus A(H1N1)pdm09 fue significativa de un 34,7\% aunque inferior a la alcanzada en otros estudios. En los resultados recogidos por el I-MOVE ${ }^{9}$ la efectividad frente a este subtipo viral es del 44,2\% (IC95\%: $-3,1 ; 69,8)$. Frente a una efectividad del 64\% (IC95\%: 4477) obtenida en un estudio realizado en Canadá ${ }^{12}$.

La distribución por sexos del total de hospitalizaciones registradas durante la temporada en el Área estudiada fue similar. Cabe destacar el número de gestantes que necesitaron ser ingresadas durante la temporada, 21, que suponen el $8 \%$ de ingresados frente al $3 \%$ de la temporada previa. Además, al analizar la frecuencia que suponen según el número total de mujeres en edad fértil que ingresaron (considerando edad fértil entre los quince y cuarenta y nueve años de edad) nos encontramos con que son el $67,7 \%$ de este grupo, mientras que en España supusieron solamente el 14\% de las mujeres en edad fértil ${ }^{5}$. El embarazo supone el mayor factor de riesgo para ingresar por gripe en mujeres menores de 40 años, en este grupo poblacional está indicada la vacunación antigripal en cualquier momento del embarazo y, sin embargo, en 
Tabla 4. Efectividad vacunal en el Área de Vigo durante la temporada 2015-2016.

\begin{tabular}{|c|c|c|c|c|c|}
\hline & Casos & Controles & $\mathrm{EV}$ a \% & IC $95 \%{ }^{b}$ & $p$-value \\
\hline \multicolumn{6}{|c|}{ EV prevención ingreso } \\
\hline Vacunados & 64 & 171 & $34,7 \%$ & $(7,1 ; 54,1)$ & 0,011 \\
\hline No vacunados & 145 & 253 & & & \\
\hline \multicolumn{6}{|c|}{ EV prevención ingreso grave } \\
\hline Vacunados & 25 & 171 & $44,7 \%$ & $(9,1 ; 66,5)$ & 0,012 \\
\hline No vacunados & 67 & 253 & & & \\
\hline \multicolumn{6}{|c|}{ EV prevención ingreso UCI } \\
\hline Vacunados & 3 & 171 & $79,8 \%$ & $(31,5 ; 94,1)$ & 0,002 \\
\hline No vacunados & 22 & 253 & & & \\
\hline \multicolumn{6}{|c|}{ Mujeres } \\
\hline Vacunados & 39 & 83 & $30,9 \%$ & $(-10,4 ; 56,7)$ & 0,075 \\
\hline No vacunados & 87 & 128 & & & \\
\hline \multicolumn{6}{|c|}{ Hombres } \\
\hline Vacunados & 25 & 88 & $38,7 \%$ & $(0 ; 64,4)$ & 0,049 \\
\hline No vacunados & 58 & 125 & & & \\
\hline \multicolumn{6}{|c|}{ Mayores de 60 años } \\
\hline Vacunados & 53 & 135 & $37,0 \%$ & $(0 ; 60,5)$ & 0,034 \\
\hline No vacunados & 53 & 85 & & & \\
\hline \multicolumn{6}{|c|}{ Mayores de 65 años } \\
\hline Vacunados & 50 & 124 & $34,0 \%$ & $(-8,6 ; 59,9)$ & 0,065 \\
\hline No vacunados & 44 & 72 & & & \\
\hline \multicolumn{6}{|c|}{ Mayores de 75 años } \\
\hline Vacunados & 34 & 86 & $26,8 \%$ & $(-37,8 ; 61,1)$ & 0,210 \\
\hline No vacunados & 24 & 46 & & & \\
\hline \multicolumn{6}{|c|}{ Virus A } \\
\hline Vacunados & 60 & 171 & $30,1 \%$ & $(0 ; 51,4)$ & 0,032 \\
\hline No vacunados & 127 & 253 & & & \\
\hline \multicolumn{6}{|c|}{ Virus A (H1N1) pdm09 } \\
\hline Vacunados & 49 & 171 & $34,7 \%$ & $(3,7 ; 55,7)$ & 0,019 \\
\hline No vacunados & 111 & 253 & & & \\
\hline \multicolumn{6}{|c|}{ Virus B } \\
\hline Vacunados & 4 & 171 & $67,1 \%$ & $(1,2 ; 89,1)$ & 0,028 \\
\hline No vacunados & 18 & 253 & & & \\
\hline
\end{tabular}

${ }^{\text {a }}$ Efectividad vacunal. ${ }^{\mathrm{b}}$ Intervalo de confianza. 
las gestantes ingresadas, la cobertura vacunal era solamente del $14,3 \%$.

En cuanto a la efectividad medida de la vacuna antigripal por sexos, encontramos una efectividad significativa en hombres, mientras que en mujeres la efectividad no es significativa, aunque podría deberse este resultado al tamaño muestral, al presentar intervalos de confianza amplios. Esto contrasta con los resultados obtenidos en el estudio elaborado sobre la temporada 2014-2015 en la misma área de salud ${ }^{11}$. Se encontraba una efectividad superior en las mujeres mayores de 65 años, debido probablemente a que en este grupo de edad los hombres acumulan un mayor número de comorbilidades, con un riesgo basal mayor. Por el contrario, en nuestra serie, esta baja efectividad puede deberse al gran número de embarazadas que ingresaron durante la temporada.

Los grupos de edad avanzada (por encima de 59 años en Galicia) son la principal diana de la vacunación antigripal. Durante la temporada estudiada, la mayoría de los ingresos se produjeron en mayores de 60 años (46,9\%), con una diferencia importante con los resultados a nivel nacional, en que el grupo de edad más afectado fue el de menores de quince años ${ }^{5}$.

Además, conforme se aumenta en la edad, se observa que los periodos de hospitalización se prolongan debido probablemente a la comorbilidad. La cobertura vacunal encontrada en los pacientes ingresados mayores de 65 años fue del 50,5\%. Se comparó la efectividad vacunal según diferentes subgrupos de edad, obteniendo una efectividad vacunal significativa y elevada para mayores de 60 años (37\%) y mayores de 65 años (34\%), similares a las alcanzadas en el estudio realizado en Dinamarca ${ }^{13}$, aunque este sólo analizaba la efectividad frente al virus A(H1N1) pdm09. Sin embargo, no se obtuvo una efectividad significativa para mayores de 75 años, que suponen el único subgrupo de edad con una vacuna específica y de administración diferente, por vía intradérmica. Esto puede deberse a que nuestro estudio mide la efectividad de la vacuna para prevenir el ingreso, y se trata del grupo de edad con mayor riesgo a ingresar por su avanzada edad y por otras patologías asociadas.

Durante la temporada, el 13,7\% de estos pacientes ingresados necesitaron cuidados críticos frente al 35\% de todas las hospitalizaciones por gripe a nivel estatal, publicado en el Informe de Vigilancia de la Gripe en España, temporada 2015$2016^{5}$. Durante el ingreso en UCI más del 80\% de los pacientes necesitaron alguna medida de soporte respiratorio, la más utilizada fue la ventilación mecánica invasiva que, además, se relacionó con un mayor número de días de hospitalización.

Respecto a la atención médica, se ha observado un ingreso hospitalario precoz, similar al de la temporada previa. En las mujeres la media de días desde el comienzo de la sintomatología hasta el ingreso es de 3,3 días, frente a los hombres, que aunque ingresan más tardíamente, presentan estancias hospitalarias más prolongadas.
Las personas menores de 60 años y mayores de 6 meses que, por tener alguna patología crónica, presentan mayor riesgo de padecer complicaciones derivadas de la gripe, deberían vacunarse con periodicidad anual. Del total de pacientes ingresados durante la temporada, más del 70\% presentaban factores de riesgo y aproximadamente la mitad de los pacientes ingresados sufrieron complicaciones derivadas de la gripe, siendo la más común la neumonía y las más graves el síndrome de distrés respiratorio agudo y el fallo multiorgánico.

El $8 \%$ de los pacientes ingresados en el CHUVI fallecieron durante la hospitalización, un porcentaje inferior al de ámbito estatal (11\%). Del total de fallecidos, un $52,4 \%$ de los pacientes ingresó en la UCl y un $85,7 \%$ fue tratado con un fármaco antiviral, siempre oseltamivir, con pauta estándar. Al mismo tiempo, se determinó un riesgo mayor de fallecer en aquellos pacientes con complicaciones graves y en pacientes de edad avanzada.

\section{Bibliografía}

1. Martínez Baz I. Evaluación de la efectividad de la vacuna antigripal: Diseño de casos confirmados por laboratorio y controles negativos a gripe [tesis doctoral en Internet]. Pamplona: Universidad Pública de Navarra; 2012. Disponible en: https://academicae.unavarra.es/bitstream/handle/2454/18341/Tesis\%20Mart\%C3\%ADnez\%20 Baz\%2C\%20lv\%C3\%A1n\%20SA\%20ma.pdf?sequence=1\&isAllowed=y

2. Paules C, Subbarao K. Influenza. Lancet. 2017;390:697-780.

3. Salleras $L$, Domínguez A. Impacto sanitario y económico de la vacunación antigripal inactivada. Vacunas. 2002;3(S1):38-46.

4. Drinka PJ, Krause P, Nest L. Clinical features of influenza A virus infection in older hospitalized persons. J Am Geriatr Soc. 2002;51:1182-1189.

5. Instituto de Salud Carlos III. Informe de Vigilancia de la Gripe en España. Temporada 2015- 2016 (Desde la semana 40/2015 hasta la semana 20/2016). Sistema de Vigilancia de la Gripe en España. [Internet] 2016 [Consultado 10 de febrero de 2017] Disponible en: http://www.isciii.es/ISCIII/es/contenidos/fd-servicios-cientifico-tecnicos/fd-vigilancias-alertas/fd-enfermedades/gripe.shtml

6. Dirección Xeral de Saúde Pública. Campaña de vacunación antigripal 2015 [Internet]. Santiago de Compostela: Consellería de Sanidade; 2015 Disponible en: https:// libraria.xunta.gal/sites/default/files/downloads/publicacion/instruccion_campana_ de_gripe_2015_castellano.pdf

7. WHO. Recommended composition of influenza virus vaccines for use in the 20152016 northern hemisphere influenza season [Internet]. 2016. Disponible en: http:// www.who.int/influenza/vaccines/virus/recommendations/201502_recommendation.pdf?ua $=1$

8. Dirección Xeral de Saúde Pública. Informe final da campaña de vacinación antigripal 2015. Santiago de Compostela: Consellería de Sanidade; 2016 Disponible en: http:// www.sergas.es/Saude-publica/Documents/3739/Informe_Campa\%C3\%B1a_vacinacion_Antigripal_2015.pdf

9. Kissling E, Valenciano M. Early influenza vaccine effectiveness results 2015-16: IMOVE multicentre case-control study. Euro Surveill [Internet] 2016 ;21(6). Disponible en: http://dx.doi.org/10.2807/1560-7917.ES.2016.21.16.30201

10. Zhang $Y$ et al. Influenza vaccine effectiveness against influenza-associated hospitalization in 2015/16 season. Beijing, China. Vaccine [Internet] 2017 35(23):31293134 Disponible en: http://dx.doi.org/10.1016/j.vaccine.2017.03.084

11. Canoa I, del Campo V (dir). Análisis de la efectividad de la vacuna antigripal 20142015 en la prevencion de gripe grave (hospitalizacion por gripe) en el área de Vigo [Trabajo Final de Grado]. Vigo: Universidad de Vigo; 2016.

12. Chambers C, Skowronski D, Sabaiduc S, Winter A, Dickinson J, De Serres G et al. Interim estimates of 2015/16 vaccine effectiveness against influenza A(H1N1)pdm09, Canada, February 2016. Euro Surveill [Internet] 2016; 21(11). Disponible en: http:// dx.doi.org/10.2807/1560-7917.ES.2016.21.11.30168

13. Emborg H, Krause TG, Nielsen L, Thomsen MK, Christiansen CB, Skov MN, Nielsen XC, Weinreich LS, Fischer TK, Rønn J, Trebbien R. Influenza vaccine effectiveness in adults 65 years and older, Denmark, 2015/16 - a rapid epidemiological and virological assessment. Euro Surveill. [Internet] 2016; 21(14). Disponible en: http://dx.doi. org/10.2807/1560-7917.ES.2016.21.14.30189 